\title{
SOURCES OF WAGE DIFFERENTIALS BETWEEN NATIVE AND IMMIGRANT WORKERS: A REGIONAL ANALYSIS
}

\author{
Nasser Daneshvary and William L. Weber*
}

\begin{abstract}
Sources of wage differential between native and all immigrant, Asian, European, and Latin American workers are examined by estimating hedonic wage equations and employing wage differential decomposition methodology. In addition the extent of interregional differences in such differential is investigated. Results show that a large portion of the wage differential is due to the level and valuation of pre-and post-migration experiences and education. However, some portion of wage differential is due to wage discrimination (residual difference). These findings are by no means uniform for all ethnic groups or for all regions of the United States. The portion of wage differential attributable to possible discrimination is highest for Latin American and nonexistent for Europeans. Overall, the estimated levels of wage discrimination against immigrants are lower, and the regional pattern of these estimates is consistent with the findings of wage discrimination studies of blacks and women.
\end{abstract}

\section{INTRODUCTION}

In recent years, issues relating to U.S. immigration have become important to analysts and policy makers. The high volume of legal immigration, in addition to substantial illegal immigration, during the 1970s has renewed interest among economists and other social scientists. A large body of recent literature has examined the economic fate of immigrants, as well as the effects of immigration on the U.S. labor market. ${ }^{1}$ This literature analyzes the relative earnings of immigrants within a human capital framework and, in general, has found the existence of an earnings differential between natives and immigrants.

The majority of the past studies have focussed on the supply side of the labor market and have addressed issues pertaining to the self-selectivity of immigrants, the comparability of pre- versus post-immigration education and experience, the quality of successive immigrant cohorts, and the ethnicity of immigrants. However, wage differentials may also exist because of labor market discrimination, a demand side consideration.

In addition, as a result of interregional differences in institutions, customs, and endowments, structures of wages as well as the extent of labor market discrimination may differ across regions. The existence of these differentials between the North and the South, and the consequent migration of blacks from

\footnotetext{
* Department of Economics, University of Nevada, Las Vegas and Southeast Missouri State University, respectively. Financial support is acknowledged from First Interstate Bank of Nevada.
} 
South to North, are well documented in the literature. ${ }^{2}$ Also, internal migration studies have long recognized the important regional consequences and policy implications regarding labor flows.

Interregional discrimination differentials, along with regional differences in wages, may also constitute an important determinant of location decision of immigrants within the United States and have important regional public policy implications. Thus it can be argued that a regional level analysis is a more appropriate basis for the study of relative wages of immigrants.

Given the above arguments, the objectives of this paper are twofold. The first is to examine both demand and supply side sources of wage differentials between natives and immigrants by estimating hedonic wage equations and employing wage differential decomposition methodology. The second objective is to explore the extent and sources of interregional differences in native-immigrant wage differentials.

\section{BACKGROUND AND LITERATURE REVIEW}

Many past empirical studies of both racial and sexual wage discrimination began with the specification and estimation of two separate reduced form wage equations for the two groups of workers involved. Using these estimates and average human capital characteristics for each group, the geometric mean of the wage differential is decomposed into an endowment effect (due to productivity differential) and a residual difference. This residual component then is attributed to wage discrimination. Accuracy of the measured wage discrimination, of course, depends on the correct specification of the two reduced form equations. Improper specification of the models, such as omitted variables, will produce an inaccurate measurement of wage discrimination.

To our knowledge, all but one of the empirical studies of the relative eamings of immigrants have assumed that wage differentials between natives and immigrants are the result of productivity differentials only. However, another contributing factor to wage differentials between native and immigrant workers may be that immigrants encounter wage discrimination. Using a national sample and employing residual difference methodology, Gabriel and Schmitz (1987) have analyzed the earnings differential between natives and immigrants. They estimated a basic human capital and an "assimilation" model of income determination and found that their "analysis produces rather inconclusive evidence of earnings discrimination against foreign-born workers, but does suggest that the analysis is sensitive to slight change in model specification" (p. 99). However, both models included the human capital characteristics of workers as the only ex- 
planatory variables. This implicitly assumes that all workers, regardless of occupation, industry, and region, participate in a common aggregate national labor market. To the extent that returns to the individual human capital attributes are influenced by market-specific characteristics, estimation of an "only human capital variables" model may not produce an accurate measure of discrimination.

In this paper we allow returns to human capital variables to vary across occupations, industries, and regions. This approach is consistent with a hedonic interpretation of wage equations. The hedonic wage equation is equivalent to the traditional human capital wage function applied to a particular labor market. ${ }^{3}$

\section{MODEL SPECIFICATION}

Following Low and Villegas (1987), general hedonic wage equations for native-born and foreign-born workers may be written as:

$$
\begin{aligned}
& \ln W^{n}=a^{n}+b^{n} X^{n}+U^{n}, \\
& \ln W^{f}=a^{f}+b^{f} X^{f}+U^{f},
\end{aligned}
$$

where $\mathrm{W}$ is the equilibrium wage, $\mathrm{X}$ is a vector of human capital characteristics, a is an intercept term, $b$ is the vector of hedonic prices, and $U$ is an error term. In the tradition of the human capital model, vector $\mathbf{X}$ includes years of school, years of potential labor market experience, and its square (Mincer 1974). However, previous empirical research of immigrant earnings has found differences in the valuation (hedonic prices) of labor market experience acquired prior to immigration and experience acquired in the U.S. labor market. ${ }^{4}$

A modification to the above general model has been suggested by the assimilation literature. Following Chiswick (1978) and others, we decompose the total labor market experience (EXP) of immigrant workers into pre-immigration (EXPB) and post-immigration (EXPA) experience. In addition, the assimilation literature has found that country of origin is an important determinant of immigrant earnings. Thus, a binary variable regime is included to capture country/subregion differentials that may affect wages. ${ }^{5}$ Incorporating the above modifications, equation (1) and (2) can be transformed to:

$$
\ln W^{n}=a^{n}+b_{i}^{n}(E D U)^{n}+b_{2}^{n}(E X P)^{n}+b_{3}^{n}\left(E X P^{2}\right)^{n}+U^{n},
$$




$$
\begin{aligned}
& \ln W^{f}=a^{f}+b_{1}^{f}(E D U)^{f}+b_{2}^{f}(E X P B)^{f}+b_{3}^{f}\left(E X P B^{2}\right)^{f}+b_{4}^{f}(E X P A)^{f}+ \\
& b f\left(E X P A^{2} f^{f}+b_{6}^{f}(E X P B)^{f} *(E X P A)^{f}+\sum_{i} c_{i}^{f}(O R)_{i}^{f}+U^{f},\right.
\end{aligned}
$$

where (ORI) is a vector of country/subregion binary variables and (EXPB)* (EXPA) represents interaction between pre-immigration and post-immigration experience. One interpretation of this term is that the effect of post-immigration experience on wage growth is not independent of pre-immigration experience (Fujii and Mak 1983, 767). For the sake of clarity, we call equations (3) and (4) the "basic" model. 6

As discussed before, applying the above wage equations to a national sample implicitly assumes that all workers participate in a common aggregate national labor market and that the extent of wage discrimination is the same across all regions, occupations, and industries. However, many empirical studies of blackwhite and female-male wage differentials have found significant differences in the wage structure among regions, occupations, and industries (Hanushek 1981), (Kiefer and Smith 1977), and (Low and Villegas 1987). This observation suggests an alternative methodology to the basic model.

To the extent that the regional, occupational, and industrial distributions of immigrant workers in the United States differ from those of native workers, the residual difference based on a national sample and "human capital variables only" does not produce an accurate measure of discrimination. An alternative approach is to obtain regional hedonic prices (allowing "returns" to the human capital variables to vary across occupations and industries) by estimating separate equations for each of the regional labor markets. In the empirical section below, separate equations for the United States, North, and South are estimated. ${ }^{7}$

Inclusion of occupation and industry variables in a hedonic wage equation can be justified along two distinct lines of reasoning. First, occupation and industry may be included as proxies for some unobserved human capital that affect productivity. Some occupations and industries may have a greater demand for these unobserved characteristics and attract individuals with greater endowment of these characteristics. ${ }^{8}$ Under these circumstances, observed human capital characteristics, as well as occupation and industry variables, enter the hedonic wage equation separately.

A second line of reasoning for inclusion of occupation and industry variables may be the existence of differential market valuation of observed human capital variables across occupations and industries. This is equivalent to arguing that hedonic prices of observed characteristics vary across occupations and industries. In this case, the econometric specification of the hedonic wage functions must in- 
clude observed human capital characteristics, as well as an interaction between each of these characteristics and occupation/industry.

In addition, it can be argued that occupation and industry enter the hedonic wage equations because of the existence of both differential market valuation of observed human capital and unobserved characteristics affecting productivity. Under this assumption an alternative specification of the hedonic wage equations may be written as:

$$
\begin{aligned}
& \ln W^{n}=Z^{n} \beta^{n}+Y^{n} \tau^{n}+\left(Z^{n} Y^{n}\right) \delta^{n}+U^{n}, \\
& \ln W^{f}=Z^{f} \beta^{f}+Y^{f} \tau^{f}+\left(Z^{f} Y^{f}\right) \delta^{f}+U^{f},
\end{aligned}
$$

where vectors $\mathbf{Z}^{\mathrm{n}}$ and $\mathbf{Z}^{\mathbf{f}}$ represent all explanatory variables in equations (3) and (4) respectively, $Y$ is a vector of occupation and industry binary variables, and (ZY) is a vector of interactions between occupation/industry and the human capital variables in each equation. This full interactive model is equivalent to estimating a separate equation for each occupation and each industry and shall be referred to as the "fully interactive" model.

In the following section, two specifications of the wage equation ("basic" and "fully interactive" models) are estimated. The estimates of these wage models are then used to decompose the difference in the geometric means of the observed wages of native and immigrant workers into the endowment effect and the residual difference. ${ }^{9}$ Comparison of the estimated residual difference obtained from each of the two specifications allows us to assess the impact of occupation and industry variables on the estimated portion of wage differentials due to wage discrimination. In addition, it is assumed that native and immigrant workers with identical characteristics are perfect substitutes and equally productive. Thus, the marginal products of "alike" workers are invariant to the quantity of workers employed from each group. ${ }^{10}$

\section{ECONOMETRIC RESULTS}

\section{A. Data and Variables}

The research population for the examination of wage differentials between native and immigrant workers was confined to the non-black, male component of the U.S. labor force (both natives and immigrants) in order to control for sex-re- 
lated interruptions (and the measured experience) and possible sex and race-related wage discrimination. Individuals were required to be of age 24-65 and to have participated in the civilian labor force in 1980, as well as to have worked some time during 1979 (the year in which wage is to be measured). The selfemployed and individuals with any disability that limits work, as well as individuals attending college in 1980, were excluded from this population to better represent the hedonic wage determination described previously. The regional labor market heterogeneity problems were reduced through the exclusion of workers residing in non-SMSA areas (about 95 percent of immigrants live within SMSAs).

Both an immigrant and a native sample of this population were obtained from the 5 percent one-in-a-thousand Public Use Sample of the 1980 Census (U.S. Bureau of the Census, 1983). The immigrant sample of 13,825 individuals was confined to those who perceived themselves as not having difficulty speaking English. A 15 percent random subsample of natives (15,204 individuals) was obtained for the purpose of wage comparison. The natural logarithm of 1979 weekly earnings (wage and salary income) was regressed against a varying set of independent variables based upon the two wage models discussed in section III. ${ }^{11}$

Estimation of the "basic" model is based on equations (3) and (4). Education is measured by years of schooling, and experience is measured as age minus education minus five. For immigrants, total experience is decomposed into preimmigration and post-immigration experience by utilizing years since immigration. In addition, the equation for immigrants includes binary variables for country/subregion using immigrants from Australia, New Zealand, Canada, and Northern and Western Europe as the reference group.

In addition to the above variables, the "fully interactive" model [equations (5) and (6)] also includes both occupation and industry and is represented by binary variables. The former are identified as "primary" white-collar (managerial and professional), "secondary" (other) white-collar, and blue-collar workers (service workers serve as the reference group). The latter comprise employment in agriculture-mining-construction, manufacturing-nondurable, manufacturingdurable, transportation, wholesale trade, retail trade, financial, and service industries (employment in agriculture-mining-construction serve as the reference group). Also included in this model are interaction terms between occupation/industry binary variables and variables reflecting the human capital characteristics of workers. ${ }^{12}$

The sample means of socioeconomic characteristics of natives and immigrants for the United States, North, and South are provided in Table 1. This table indicates differences in several variables between the natives and the immigrants. It also reveals differences between the mean characteristics of im- 
TABLE 1

Sample Means, Native and Immigrant, Males Age 24-65

\begin{tabular}{|c|c|c|c|c|c|c|}
\hline \multirow[b]{2}{*}{ Characteristics } & \multicolumn{2}{|c|}{ U.S. } & \multicolumn{2}{|c|}{ North } & \multicolumn{2}{|c|}{ South } \\
\hline & Native & Foreign & Native & Foreign & Native & Foreign \\
\hline 1979 weekly eamings & 334.80 & 312.30 & 353.50 & 314.50 & 322.10 & 302.80 \\
\hline Education & 15.236 & 14.950 & 15.277 & 14.818 & 15.121 & 15.600 \\
\hline U.S. experience & 20.432 & 11.973 & 20.677 & 12.206 & 19.753 & 10.896 \\
\hline $\begin{array}{l}\text { Experience before } \\
\text { immigration }\end{array}$ & N/A & 7.271 & N/A & 7.273 & N/A & 7.262 \\
\hline \multicolumn{7}{|l|}{ Industry: } \\
\hline \multicolumn{7}{|l|}{ Agriculture, mining, } \\
\hline Mfg.-nondurable & 0.096 & 0.104 & 0.091 & 0.110 & 0.110 & 0.075 \\
\hline Mfg.-durable & 0.223 & 0.234 & 0.251 & 0.255 & 0.146 & 0.138 \\
\hline \multicolumn{6}{|l|}{ Transp., comm., \& other } & 0.084 \\
\hline Wholesale trade & 0.059 & 0.050 & 0.057 & 0.048 & 0.065 & 0.060 \\
\hline Retail trade & 0.100 & 0.124 & 0.095 & 0.120 & 0.112 & 0.139 \\
\hline \multicolumn{6}{|l|}{ Finance, insurance, and } & 0.055 \\
\hline $\begin{array}{l}\text { Professional and related } \\
\text { services }\end{array}$ & 0.241 & 0.253 & 0.240 & 0.238 & 0.245 & 0.323 \\
\hline \multicolumn{7}{|l|}{ Occupation: } \\
\hline \multicolumn{7}{|l|}{ Managerial or } \\
\hline Other white-collar & 0.202 & 0.166 & 0.198 & 0.160 & 0.214 & 0.191 \\
\hline Blue-collar & 0.432 & 0.419 & 0.435 & 0.438 & 0.422 & 0.331 \\
\hline Service & 0.075 & 0.115 & 0.078 & 0.116 & 0.068 & 0.108 \\
\hline \multicolumn{7}{|l|}{ Country/Region of origin: } \\
\hline \multicolumn{7}{|l|}{ Europe } \\
\hline Westem \& Northem & N/A & 0.230 & N/A & 0.233 & N/A & 0.217 \\
\hline Southem & N/A & 0.130 & N/A & 0.148 & N/A & 0.045 \\
\hline Eastem & N/A & 0.084 & N/A & 0.093 & N/A & 0.039 \\
\hline \multicolumn{7}{|l|}{ Americas } \\
\hline South \& Central & N/A & 0.095 & N/A & 0.093 & N/A & 0.108 \\
\hline Mexico & N/A & 0.138 & N/A & 0.133 & N/A & 0.156 \\
\hline Cuba & N/A & 0.057 & N/A & 0.026 & N/A & 0.199 \\
\hline \multicolumn{7}{|l|}{ Asia } \\
\hline East & N/A & 0.061 & N/A & 0.063 & N/A & 0.051 \\
\hline Southwest & N/A & 0.061 & N/A & 0.058 & N/A & 0.073 \\
\hline Southeast & N/A & 0.014 & N/A & 0.014 & N/A & 0.013 \\
\hline Middle East & N/A & 0.026 & N/A & 0.028 & N/A & 0.019 \\
\hline Japan & N/A & 0.018 & N/A & 0.019 & N/A & 0.015 \\
\hline Philippines & N/A & 0.054 & N/A & 0.061 & N/A & 0.023 \\
\hline Vietnam & N/A & 0.010 & N/A & 0.008 & N/A & 0.021 \\
\hline Africa & N/A & 0.023 & N/A & 0.024 & N/A & 0.021 \\
\hline Number of observations & 15,204 & 13,825 & 11,177 & 11,371 & 4,027 & 2,454 \\
\hline
\end{tabular}

Note: $\mathrm{N} / \mathrm{A}=$ not applicable. 
migrants residing in the North and the South. For example, there are some disadvantages in weekly eamings of immigrants in both regions. But this disadvantage is much smaller for immigrants residing in the South than for those in the North (a native-immigrant difference in mean weekly earnings of $\$ 19.30$ for South vs. $\$ 39.00$ for North).

Notice in Table 1 that the average years of education is almost the same for natives living in the North and as for those residing in the South. But immigrants in the South have about eight-tenths of a year higher education than their counterparts in the North. In fact, immigrants in the South have the highest years of education among the six samples.

Table 1 also reveals differences in occupational and industrial distributions between natives and immigrants. Compared to natives, immigrants tend to be more "primary" white-collar and service workers and less "secondary" white-collar and blue-collar workers. However, there are significant differences regarding occupational and industrial distributions of immigrants between the South and the North. For example, while the portion of the native labor force employed in the service industry is almost the same in both the South and the North, that of immigrants is quite different (23.8 percent for North vs. 32.3 percent for South).

In addition, the occupational distributions of natives in the North, natives in the South, and immigrants in the North are similar. However, immigrants in the South have a significantly different occupational distribution. They tend to be more white-collar and less blue-collar than workers in the North (34 percent vs. 28.6 percent and 33.1 percent vs. 43.8 percent, respectively). Finally, as expected, some differences exist in the distribution of immigrants by origin between the North and South. For example, Southern and Eastern European immigrants tend to be more concentrated in the North than in the South, while the reverse is true for Latin Americans.

Overall, information provided in Table 1 indicates significant differences in regional, occupational, and industrial distribution between immigrants and native workers, as well as significant differences between the characteristics of immigrants in the South and in the North.

\section{B. Parameter Estimates}

The first step in obtaining a measure of discrimination involves estimation of the parameters (hedonic prices) of the wage equations for native and immigrant workers. Both wage models, outlined above, were separately estimated for native and immigrant workers for the United States, North, and South (a total of nine equations). The estimated coefficients (not presented, but available upon request) 
are consistent with the findings of other studies of both native and immigrant earnings determination. In this regard, 1979 male eamings are augmented by additional years of education and potential experience (albeit at a declining rate for the latter). However, the "returns" to education are uniformly greater for native workers than for immigrants and are uniformly higher in the South than in the North (by one percentage point). The "returns" to post-immigration experience are greater than those of overall experience for natives (except for the South), suggesting the rapid rise in immigrant earnings as they acquire U.S. work experience. In addition, the coefficients of pre-immigration experience are uniformly smaller than those of overall experience of natives and post-immigration experience of immigrants. This coefficient is higher for the South than for the North (3.9 vs. 1.8). As expected, the U.S. labor market values experience acquired prior to immigration less than experience acquired in the United States. The coefficient of the interaction term between pre-immigration and post-immigration experience is negative and significant in all cases. Finally, inclusion of occupation and industry variables affect the hedonic prices of education and experience.

\section{Wage Decomposition and Residual Difference Estimates}

Given the estimated hedonic parameters of the wage equations, the difference in the logarithm of the geometric mean wages between native and immigrant workers can be decomposed into the endowment effect and the residual difference.

Tables 2 and 3 analyze the sources of wage differentials for the total United States, as well as for the North and South. In each table, part A represents the gross wage differential, and part B provides the contribution of each explanatory variable to the wage differential. Summation of these contributions over all explanatory variables provides the endowment effect. Part $C$ of Tables 2 and 3 reports the unexplained portion or residual difference of the wage differential; it is an estimate of the level of discrimination. ${ }^{13}$ The last row in each table shows the estimated percentage of the wage differential due to discrimination. These figures are obtained by dividing the residual difference by the gross wage differential.

Confining our attention to Table 2, notice that the "basic" models indicate some wage discrimination against immigrants (between 7.2 and 37.1 percent of the earnings differential), even after accounting for the assimilation effect [see equation (4) in section III]. In addition, notice that in all three samples a large portion of the wage differential is due to the level and market valuation of immigrants' overall experience. In contrast, education provides a different picture. The results for the United States and the North indicate that immigrants are some- 
TABLE 2

Decomposition of the Native/Immigrant 1979

Weekly Wage Differential: "Basic" Model

(Expressed in Logarithm)

\begin{tabular}{llll} 
Source of Differential $^{(b)}$ & U.S. & North & South \\
\hline A. Gross wage differential & 0.0994 & 0.1174 & 0.0622
\end{tabular}

B. Due to average characteristics

(Endowment effect)

\begin{tabular}{|c|c|c|c|}
\hline Education & 0.0202 & 0.0309 & -0.0325 \\
\hline Overall experience & 0.0720 & 0.0696 & 0.0716 \\
\hline Pre-immigration experience ${ }^{(c)}$ & -0.1126 & -0.0992 & -0.1753 \\
\hline Post-immigration experience & 0.1110 & 0.1024 & 0.1407 \\
\hline Experiences interaction & 0.0736 & 0.0664 & 0.1062 \\
\hline Subtotal & 0.0922 & 0.1005 & 0.0391 \\
\hline Residual difference & 0.0072 & 0.0169 & 0.0231 \\
\hline $\begin{array}{l}\text { mated } \% \text { of the wage differential } \\
\text { e to residual difference, }(\mathrm{C} / \mathrm{A})\end{array}$ & $7.2 \%$ & $14.4 \%$ & $37.1 \%$ \\
\hline
\end{tabular}

a. All explanatory variables are defined in the text. In addition, for natives the country/subregion variables and their coefficients are assumed to be a null vector. For immigrants, the effect of these variables as well as the constant term are included in the residual difference.

b. A negative value in this table indicates a difference in favor of immigrants.

c. For native wage equations, years of pre-immigration and post-immigration experience are assumed to be equal to zero and total labor market experience, respectively.

what disadvantaged with regard to education. The reverse is true for those residing in the South. This regional difference in education-earning relationship may be a result of a large number of Cubans with extensive human capital residing in the South. To examine this possibility, the analysis was repeated with Cubans omitted from all samples. The only noticeable changes in the results were a decline (from .0622 to .0482) in gross wage differential and an increase in the coefficient and therefore the endowment effect of pre-immigration (from .1753 to .2012) for the South. A plausible explanation for this outcome is that pre-immigration experiences (skills) of Cubans are not as transferable as those of an "average" U.S. immigrant. 
TABLE 3

Decomposition of the Native/Immigrant 1979

Weekly Wage Differential: "Fully Interactive" Model

(Expressed in Logarithm) ${ }^{\mathrm{a}}$

\begin{tabular}{llll}
\hline Source of Differential & (b) & U.S. North & South \\
\hline
\end{tabular}

A. Gross wage differential

$0.0994 \quad 0.1174$

0.0622

B. Due to average characteristics

(Endowment effect)

Education

Overall experience

Pre-immigration experience ${ }^{(c)}$

0.0065

0.0032

$-0.0034^{(\mathrm{d})}$

Post-immigration experience

0.0651

0.0642

$0.0596^{(\mathrm{d})}$

$-0.1072$

$-0.0902$

$-0.1675^{(d)}$

0.0956

0.0872

$0.1245^{(d)}$

Experiences interaction

0.0767

0.0672

$0.1026^{(\mathrm{d})}$

Occupation

0.0058

0.0104

$-0.0102$

Industry

0.0262

0.0383

$-0.0082$

\section{Subtotal}

0.1037

0.1161

0.0378

C. Residual difference

$-0.0043$

0.0013

0.0244

Estimated \% of the wage differential due to residual difference, $(\mathrm{C} / \mathrm{A})$ $---1.1 \%$ $39.2 \%$

a. All explanatory variables are defined in the text. In addition, for natives the country/subregion variables and their coefficients are assumed to be a null vector. For immigrants, the effect of these variables, as well as the constant term, are included in the residual difference.

b. A negative value in this table indicates a difference in favor of immigrants.

c. For native wage equations, years of pre-immigration and post-immigration experience are assumed to be equal to zero and total labor market experience, respectively.

d. Effects of the interaction between education/experiences with occupation/industry are included in these figures.

The results reported in Table 2 are based on the implicit assumption that the level of discrimination is uniform toward all immigrants regardless of their origin. To provide insights regarding the differential treatment of immigrants from different regions, separate analyses were performed for Asians, Europeans, and Latin Americans. Decomposition results are presented in Table 4 and are briefly summarized here. In this respect, the gross wage differential between natives and Asian immigrants is about 11 percent in favor of natives residing in the North and 


\section{TABLE 4}

Decomposition of the Native/Immigrant 1979

Weekly Wage Differential: By Region of Origin

(Expressed in Logarithm) ${ }^{a}$

\begin{tabular}{|c|c|c|c|}
\hline Source of Differential & U.S. & North & South \\
\hline \multicolumn{4}{|l|}{ Asians } \\
\hline Gross differential & 0.0760 & 0.1051 & $-0.0173^{(b)}$ \\
\hline \multicolumn{4}{|l|}{ Basic model } \\
\hline Endowment effect & 0.0270 & 0.0494 & -0.0915 \\
\hline Residual difference & 0.0490 & 0.0557 & 0.0742 \\
\hline \multicolumn{4}{|l|}{ Fully interactive model } \\
\hline Endowment effect & 0.0230 & 0.0543 & -0.0863 \\
\hline Residual difference & 0.0530 & 0.0508 & 0.0690 \\
\hline \multicolumn{4}{|l|}{ European } \\
\hline Gross differential & -0.0283 & -0.0051 & -0.0852 \\
\hline \multicolumn{4}{|l|}{ Basic model } \\
\hline Endowment effect & 0.0315 & 0.0415 & -0.0674 \\
\hline Residual difference & -0.0598 & 0.0466 & -0.0178 \\
\hline \multicolumn{4}{|l|}{ Fully interactive model } \\
\hline Endowment effect & 0.0410 & 0.0530 & -0.0546 \\
\hline Residual difference & -0.0693 & -0.0581 & -0.0306 \\
\hline \multicolumn{4}{|l|}{ Latin American } \\
\hline Gross differential & 0.3122 & 0.3533 & 0.2015 \\
\hline \multicolumn{4}{|l|}{ Basic model } \\
\hline Endowment effect & 0.2570 & 0.2856 & 0.1739 \\
\hline Residual difference & 0.0552 & 0.0677 & 0.0277 \\
\hline \multicolumn{4}{|l|}{ Fully interactive model } \\
\hline Endowment effect & 0.2704 & 0.2956 & 0.1807 \\
\hline Residual difference & 0.0418 & 0.0577 & 0.0208 \\
\hline
\end{tabular}

\footnotetext{
- All explanatory variables are defined in the text. In addition, country variables and their coefficients are assumed to be a null vector for natives. For immigrants, the effect of these variables as well as the constant term are included in the residual difference.
}

b A negative value in this table indicates a difference in favor of immigrants.

about 2 percent in favor of immigrants residing in the South. However, the residual differences point toward wage discrimination in both regions (estimates of the discrimination coefficient are about 5 and 7 percent for North and South, respectively). The gross wage differential and the residual difference are in favor 
of Europeans and are against Latin Americans in all cases. For Latin Americans residing in the North, the gross differential is about 42 percent, and about 16 to 19 percent of it is attributed to discrimination. The corresponding figures for those residing in the South are 22 and 10 to 13 percent.

Comparing the decomposition based on the "fully interactive" models in Table 3 with that of the "basic" models in Table 2, notice that inclusion of occupation/industry variables reduces (increases) the estimates of the residual difference and therefore the percent of the wage differential due to discrimination for the North (South). These variations in the estimates of the residual difference are net results of two changes caused by the introduction of occupation and industry variables in the wage equations. First, estimates of education and experiences parameters change. In this regard, the results of the "fully interactive" model point toward the same regional patterns as those discussed in reference to the "basic" model, but of lesser magnitude. Second, the endowment effect changes due to new terms. Notice that the direct impact of occupation/industry variables on the endowment effect are positive for the United States and North, but negative for the South. These results seem to suggest that immigrants, relative to natives, are somewhat underrepresented in high paying occupations/industries in the North and have a slight advantage in the South. ${ }^{14}$

These findings indicate that there is a great deal of interregional difference in estimates of discrimination against immigrants. The gross wage differential in the South is almost half of that in the North, but a significantly larger portion is the result of pay discrimination in the South. However, relative to the North, the South attracts more educated immigrants by providing better opportunities for employment in high paying occupations and industries and by offering higher "returns" to education. In addition, pre-immigration experience is "valued" more in the South than in the North.

\section{CONCLUSION}

This study has examined possible sources of wage differentials between native and immigrant workers, a dimension of the immigration issue whose empirical investigation has been precluded by the majority of past research. Based on the assumption of perfect substitutability of the two groups of workers, the residual difference methodology is applied to both the traditional human capital model of wage determination and the hedonic wage equations. Assuming the absence of model misspecification and of supply side differences between natives and immigrants, the estimated residual differences then are interpreted as a measure of discrimination. 
For the United States, the results from the human capital approach indicate a relatively small portion of wage differential ( 7.2 percent) due to possible discrimination while the hedonic approach does not demonstrate such results. However, these findings are by no means uniform for all regions of the United States. In this regard, both approaches demonstrate that a relatively significant portion of the wage differential between natives and immigrants who are residing in the South may be due to discrimination (between 37.1 to 39.2 percent). The comparable figures for those residing in the North are between 1.1 to 14.4 percent. Our results also suggest that the estimated wage discrimination against the immigrant labor force is lower than the estimates of wage discrimination against native blacks and women reported by other studies.

In addition, comparison of the results obtained from the human capital models with those obtained from the hedonic equations indicate that the hedonic analysis does not necessarily produce higher or lower estimates of residual difference (discrimination). However, the results allude to possible employment (occupation/industry) discrimination in the North, an issue to be investigated in future research.

\section{ENDNOTES}

1. For examples of this work, see Borjas $(1985,1987)$, Chiswick (1978, 1986), Gabriel and Schmitz (1987), Long (1980), Reimers (1983), and Stewart and Hyclak (1984). An excellent survey of this literature is provided by Greenwood and McDowell (1986).

2. For example, in examining the migration of blacks and whites from the rural South to the urban North over the period 1900-1950, Fligstein (1981) argues that changes in the social relations of production (including discrimination) played a more important role than did wage differential between the regions.

3. The notion of a particular labor market used here refers to a specific occupation, industry, and region. For a theoretical explanation of the hedonic wage model, see Low and Villegas (1987).

4. See Chiswick (1978), Fujii and Mak (1983), Steward and Hyclak (1984), and Gabriel and Schmitz (1987). The same case may be made for pre-immigration versus post-immigration education. However, the aforementioned studies found little or no difference between the returns of education acquired before and after immigration.

5. Chiswick (1978) has highlighted these differentials as aspects of a worker's unobserved human capital characteristics which affect productivity, and thus wages. However, it is also possible that part of the wage differential across 
ethnicity is due to different degrees of labor market discrimination across ethnic groups.

6. The wage specification for immigrants (equation 4) is an "assimilation" model. However, it is equivalent to the human capital eamings function in the tradition of Chiswick (1978).

7. Separate analysis for the Northeast, North Central, South, and West were performed. However, the results for Northeast, North Central, and West were very similar. Thus, these three regions were aggregated into "North."

8. This line of reasoning for inclusion of occupation and industry variables as unobserved human capital is consistent with Chiswick's explanation for the weaker measured effect of schooling for foreign-born rather than that of nativebom (Chiswick 1978, 912). Also, for a brief discussion of interindustry wage differentials, see Thaler (1989).

9. See Blinder (1973) and Oaxaca (1973). For a critique of the wage decomposition method of measuring discrimination, see Jones (1983) and Cotton (1988).

10. It may be argued that controlling for occupation and industry would eliminate some of the effect of occupational barriers faced by immigrants, thereby producing an underestimated value for the residual difference. However, it is plausible to assume that workers employed in the same occupation and industry are more likely to be perfect substitutes than otherwise. Thus, inclusion of these variables in the wage equation is more likely to result in an accurate measure of the residual difference.

11. Weekly earnings were obtained by dividing 1979 annual earnings by weeks worked during 1979. Although hourly wages are more desirable, it is not advisable to divide the weekly earnings by hours worked in a week because reported hours worked pertain to the census reference week in 1980. See Herzog, Hofler and Schlottmann (1985).

12. Inclusion of occupation and industry binary variables, as well as interaction terms, is most likely to introduce some degree of multicollinearity. However, several F-tests for inclusion of occupational binaries only, industrial binaries only, combined occupational/industrial binaries, and combined occupational/industrial binaries and interaction terms were in all cases significant at .01 level.

13. The authors wish to thank an anonymous referee of this journal for suggesting caution in interpreting the residual difference as a measurement of discrimination. The residual difference can arise from either discrimination or from model misspecification. The latter may be due to potential supply side differences between immigrants and natives that are not accounted for by the estimated wage models (Polachek 1975).

14. The estimation and decomposiiton analyses were also repeated for each one of the four occupational groups. The gross differentials ranged from a high of 
17 percent for service workers in the North to a low of 3 percent for "primary" white-collar workers in the South. These differentials were about 10 to 12 percent for blue-collar and for "secondary" white-collar workers. The endowment effect counts for the entire wage differential among blue-collar workers, while it counts for 28 to 48 percent of that among "secondary" white-collar workers (the only occupation which showed possible discrimination were among "primary" white-collar workers [ 80 percent of the 3 percent gross differential] and among service workers [entire 10 percent of the gross differential]) residing in the South.

\section{REFERENCES}

Blinder, Alan S. "Wage Discrimination: Reduced Form and Structural Estimates." Journal of Human Resources 8 (1973): 436-455.

Borjas, George J. "Assimilation, Changes in Cohort Quality, and the Earnings of Immigrants." Journal of Labor Economics 3 (1985): 463-489.

"Self-Selection and the Earnings of Immigrants." The American Economic Review 77 (1987): 531-553.

Carliner, Geoffrey. "Wages, Earnings and Hours of First, Second and Third Generation American Males." Economic Inquiry 18 (1980): 87-102.

Chiswick, Barry R. "The Effect of Americanization on the Earnings of Foreign-bom Men." Journal of Political Economy 86 (1978): 897-921.

Chiswick, Barry R. "Is the New Immigrantion Less Skilled than the Old?" Journal of Labor Economics 4 (1986): 168-192.

Cotton, Jeremiah. "On the Decomposition of Wage Differentials." The Review of Economics and Statistics 70 (1988): 236-243.

Fligstein, Neil. Going North: Migration of Blacks and Whites from the South, 1900-1950. New York: Academic Press, 1981.

Fujii, Edwin, and James Mak. "The Determinants of Income of Native-and Foreign-Born Men in a Multiracial Society." Applied Economics 15 (1983): 759-776.

Gabriel, Paul E., and Susanne Schmitz. "The Relative Eamings of Native and Immigrant Males in the United States." Quarterly Review of Economics and Business 27 (1987): 91-101.

Greenwood, Michael J., and John M. McDowell. "The Factor Market Consequences of U.S. Immigration." Journal of Economic Literature 24 (1986): 1738-1772.

Hanushek, Eric A. "Alternative Models of Earnings Determination and Labor Market Structures." Journal of Human Resources 16 (1981): 238-259. 
Herzog, Henry, Jr., Richard Hofler, and Alan M. Schlottmann. "Life on the Frontier: Migrant Information, Earnings and Past Mobility." The Review of Economics and Statistics 67 (1985): 373-382.

Jones, F. L. "On Decomposing the Wage Gap: A Critical Comment on Blinder's Method." Journal of Human Resources 18 (1983): 126-130.

Kiefer, Nicholas M., and Sharon P. Smith. "Union Impact and Wage Discrimination by Region." Journal of Human Resources 12 (1977): 521-534.

Long, James E. "The Effect of Americanization on Earnings: Some Evidence for Women." Journal of Political Economy 88 (1980): 620-629.

Low, Stuart A., and Daniel S. Villegas. "The Analysis of Wage Differentials." Southern Economic Journal 54 (1987): 449-462.

Mincer, Jacob. Schooling, Experience, and Earnings. New York: Columbia University Press, 1974.

Polachek, Solomon W. "Potential Biases in Measuring Male-Female

Discrimination." Journal of Human Resources 10 (1975): 205-229.

Oaxaca, Ronald. "Male-Female Wage Differentials in Urban Labor Markets." International Economic Review 14 (1973): 693-709.

Reimers, Cordelia W. "Labor Market Discrimination Against Hispanic and Black Men." The Review of Economics and Statistics 65 (1983): 570-579.

Stewart, James B., and Thomas Hyclak. "An Analysis of the Earnings Profiles of Immigrants." The Review of Economics and Statistics 66 (1984): 292-296.

Thaler, Richard H. "Interindustry Wage Differentials." Journal of Economic Perspectives 3 (1989): 181-193. 